\title{
Identification of Water and Nitrogen Stress Indicative Spectral Bands Using Hyperspectral Remote Sensing in Maize During Post-Monsoon Season
}

\author{
B. Balaji Naik ${ }^{1}$ H. R. Naveen ${ }^{2} \cdot$ G. Sreenivas ${ }^{1} \cdot$ K. Karun Choudary ${ }^{3} \cdot$ D. Devkumar ${ }^{1} \cdot$ J. Adinarayana ${ }^{4}$
}

Received: 10 January 2020 / Accepted: 5 October 2020/Published online: 14 October 2020

(c) The Author(s) 2020

\begin{abstract}
Realization of agricultural crop condition through field survey is quite expensive, time consuming and sometimes not practical for remote locations. Optical remote sensing techniques can provide information on real condition of the crops by observing spectral reflectance at different crop growth phases and is less expensive and less time consuming. Hyperspectral remote sensing provides a unique opportunity for non-destructive, timely and accurate estimation of crop biophysical and biochemical properties. In this study, a field experiment was conducted to identify the water and nitrogen stress indicative spectral bands using ground-based hyperspectral data and to assess the predictive capability of selective bands on yield of maize under water and nitrogen stress environment. The experiment comprised of three irrigation scheduling treatments based on IW/CPE ration of 0.6, 0.8 and 1.2 and three nitrogen level treatments, i.e., 100, 200 and $300 \mathrm{~kg}$ of $\mathrm{N} \mathrm{ha}^{-1}$, respectively, with three replications in a split plot design. The spectral reflectance was measured before irrigation at tasseling and dough stage of the maize crop using portable field spectroradiometer. The results of stepwise multiple linear regression indicated the highest predicting capability of spectral bands $540 \mathrm{~nm}, 780 \mathrm{~nm}$ and $860 \mathrm{~nm}$ for leaf nitrogen and $700 \mathrm{~nm}, 740 \mathrm{~nm}$ and $860 \mathrm{~nm}$ for leaf water content. The derived biophysical parameters based on spectral reflectance viz. relative leaf water content $(\%)$, leaf area index and leaf nitrogen contentment (\%) at tasseling stage of maize crop accounted for $80 \%, 61 \%$ and $66 \%$ variation in grain yield, respectively.
\end{abstract}

Keywords Remote sensing $\cdot$ Maize $\cdot$ Spectral reflectance $\cdot$ Relative leaf water content $\cdot$ Leaf nitrogen $\cdot$ Leaf area index

\section{Introduction}

Remote sensing is obtaining information from an object of interest without being in physical contact with it and whose temperature is above the obsolete zero having property of

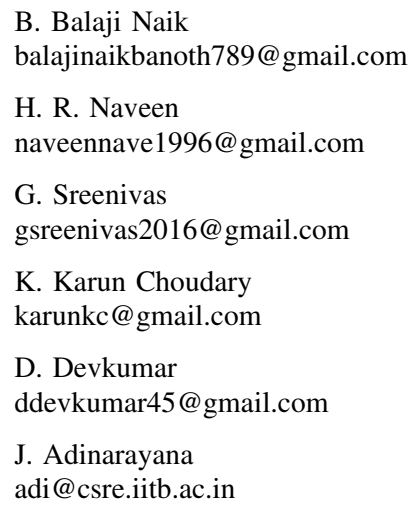


growth phases even from remote area and is less expensive, in time otherwise it is very difficult through expensive field surveys. The incident radiation influences the physical and physiological properties of crop plants and acts as a key element to understand the crop growth and its interaction with surrounding environment. From recent past, remote sensing is being used as a successful technology for continuous monitoring crop growth on spatiotemporal scale as a decision support system in agriculture. Monitoring crop growth response to water and nutrients availability at farm level and regional scale are essential for crop yield assessment. Early detection of stress prior to expression of visible symptom by the crop using hyperspectral remote sensing was reported by Panigada et al. (2010) and increased the interest of several researchers to investigate on different crops.

Maize is most important cereal crop grown worldwide with production of 1.09 BMT (US statistics, 2018-2019). More than $35.87 \%$ world maize crop production is being contributed from the USA and is largest producer of the world with a productivity of $10.57 \mathrm{t} \mathrm{ha}^{-1}$ which is almost double over world average productivity of $4.92 \mathrm{t} \mathrm{ha}^{-1}$. In India, maize is cultivated over an area of $9.2 \mathrm{~m}$ ha with production of 28.7 million tonnes and productivity of $3115 \mathrm{~kg} \mathrm{ha}^{-1}$ in 2016-2017 (FAOSTAT 2017), and it is considered as $3^{\text {rd }}$ most important crop among the cereals after rice and wheat. The productivity of maize crop is affected by various abiotic (water and nutrients) and biotic (pests and diseases) stresses. Among the abiotic factors, water and nitrogen are considered as more critical elements in deciding maize productivity (Gheysari et al. 2009). Inappropriate management of these two crucial factors causes reduction in yield as both the factors have positive correlation with maize productivity (Di Paolo and Rinaldi 2008). The application of remote sensing technology in detection of water and nutrient stress in maize on temporal scales allows accurate and precise documentation of information and is very difficult and time consuming with traditional way of field survey and sampling.

In this paper, an attempt was made to identify the water and nitrogen stress indicative spectral bands using hyperspectral remote sensing and assessed the predictive capability of selective bands on growth and yield of maize under water and nitrogen stress environment during postmonsoon season.

\section{Materials and Methods}

A field experiment was conducted at Agro Climate Research Centre, P.J.T.S Agricultural University, Hyderabad, India during rabi (winter) season of 2018-2019 with maize crop (maize hybrid Cargill $900 \mathrm{M}$ ). The site of experiment is located at $\mathrm{N} 17^{\circ} 32^{\prime \prime}$, E $78^{\circ} 39^{\prime \prime}$ and 542.3 MSL in the Southern Telangana Agro-Climatic Zone in Telangana State. The soil is sandy loam in texture and neutral in reaction with a $\mathrm{pH}$ of 7.43 . The soil was low in organic carbon (0.22\%) and available nitrogen $\left(186 \mathrm{~kg} \mathrm{ha}^{-1}\right)$ and high in available phosphorus $\left(35.3 \mathrm{~kg} \mathrm{ha}^{-1}\right)$ and potassium $\left(383 \mathrm{~kg} \mathrm{ha}^{-1}\right)$. The soil moisture holding capacity was $13.8 \%(\mathrm{w} / \mathrm{w})$ at $-0.1 \mathrm{M} \mathrm{Pa}$ and $5.25 \%(\mathrm{w} / \mathrm{w})$ at $-1.5 \mathrm{M} \mathrm{Pa}$. The experiment was laid out in split plot design replicated thrice. The treatments comprises of three irrigation levels viz. IW/CPE (irrigation Water/ Cumulative Pan Evaporation) ratio of 0.6, 0.8 and 1.2 and three nitrogen levels viz. 100, 200 and $300 \mathrm{~kg}$ of nitrogen $\mathrm{ha}^{-1}$. The crop was sowed on 16 October, 2018 and harvested at harvest maturity. The nitrogen fertilizers was applied in 3 equal splits each at basal (in the form of DAP and urea), 6 leaf stage (in the form urea) and tasseling stage (in the form urea) of the crop. The recommended entire dose of phosphorus @ $60 \mathrm{~kg}\left(\mathrm{P}_{2} \mathrm{O}_{5}\right)$ in the form of Di-ammonium phosphate applied as basal and $40 \mathrm{~kg}$ potassium $\left(\mathrm{K}_{2} \mathrm{O}\right)$ in the form of muriate of potash (MOP) was applied in 2 equal splits each at basal and tasseling stage. The field was laid out in ridges and furrows at $60 \mathrm{~cm}$ apart. The plant-to-plant spacing adopted within the row was $20 \mathrm{~cm}$. All the treatments were uniformly irrigated initially up to 15 days after sowing to ensure better establishment of the crop. The other standard management practices as recommended by the P.J.T.S. Agricultural University for the state of Telangana were followed.

\section{Relative Leaf Water Content (\%)}

The relative leaf water content (RLWC) was measured before irrigation by collecting leaf samples from each treatment and estimated by using the formula suggested by Barrs and Weatherley (1962) as expressed below.

Relative Leaf Water Content $=\frac{\text { Fresh weight }(\mathrm{g})-\text { dry weight }(\mathrm{g})}{\text { Turgid weight }(\mathrm{g})-\text { dry weight }(\mathrm{g})} \times 100$

\section{Leaf Nitrogen Content (\%)}

The exposed leaf for spectral reflectance study was collected for estimation of nitrogen content. The leaf samples at tasseling and dough stages were collected oven-dried at $65{ }^{\circ} \mathrm{C}$ powdered for analysis using Microkjeldahl method (Piper 1966).

\section{Leaf Area Index}

Leaf area was estimated on two plants in each plot at tasseling and dough stages. The area of total leaves was measured with digital leaf area meter (LI-3100) and 
expressed in $\mathrm{cm}^{-2}$. Leaf area index was calculated by using the formula as proposed by Watson (1952).

$\mathrm{LAI}=\frac{\text { Leaf area per plant }}{\text { Land area per plant }}=\frac{A}{P}$

\section{Spectral Reflectance Measurements and Data Analysis}

Non-destructive in situ spectral data were collected using Spectroradiometer (PS-100) at nadir position with $25^{\circ}$ Field of view (FOV) placed at $10-15 \mathrm{~cm}$ above the canopy. The spectral reflectance measurements were performed during bright sunny day between 11.30 am to $2.30 \mathrm{pm}$ (Darvishzadeh et al. 2008). The spectral resolution (Full width half maxima, FWHM) of PS 100 spectroradiometer was $1.6 \mathrm{~nm}$. The collected spectra were resampled to $0.5 \mathrm{~nm}$. The specifications of PS 100 spectroradiometer are mentioned in Table 1.

Target radiance was normalized by recording the radiance of a white standard panel of known reflectivity (barium sulphate coated plate) before each observation. Ten measurements of reflectance were collected within each sub-plot. The reflectance data were pre-processed for outlier removal and averaged thereafter.

\section{Selection of Effective Spectral Bands}

Multiple linear regression analysis was performed using backward elimination stepwise method and best combinations of bands were selected based on highest coefficient of determination for biophysical parameters viz. leaf nitrogen $(\%)$, relative leaf water content $(\%)$ and leaf area index. In this study, the values of biophysical parameters viz., leaf nitrogen content $(\%)$, relative leaf water content $(\%)$ and leaf area index dataset $(Y)$ were used as the dependent variables, and full bands spectra and sensitive wavelengths from 400 to $1000 \mathrm{~nm}$ averaged to $10 \mathrm{~nm}$ interval dataset $(X)$ were used as the independent variables. The $P$ value of an $F$-statistic was computed to test models with and without a potential variable at each step. The maximum
$P$ values for a spectral band to be included or removed were defined as 0.05 and 0.01 , respectively.

\section{Results and Discussion}

\section{Selective Spectral Bands in Prediction of Biophysical Parameters}

The leaf nitrogen content $(\%)$, relative leaf water content (\%) and leaf area index of maize crop were derived from reflectance of selective spectral bands and are presented in Table 1. The variation in leaf nitrogen concentration at tasseling and dough stage ranged from 1.33 to $1.82 \%$ as a result of differential nitrogen levels of $100\left(\mathrm{~N}_{1}\right), 200\left(\mathrm{~N}_{2}\right)$ and $300\left(\mathrm{~N}_{3}\right) \mathrm{kg} \mathrm{N} \mathrm{ha}^{-1}$ (Fig. 1) was explained by reflectance at green $(540 \mathrm{~nm})$ and NIR $(780 \mathrm{~nm}$ and $860 \mathrm{~nm})$ bands with coefficient of determination $\left(R^{2}\right)$ of $78 \%$ (Table 2). The spectral bands in red (700 $\mathrm{nm}$ and $740 \mathrm{~nm})$ and NIR $(860 \mathrm{~nm})$ regions were found effective with coefficient of determination $\left(R^{2}\right)$ of $77 \%$ (Table 2) for predicting relative leaf water content ranged from $66.6 \%$ to $81.1 \%$ under varied moisture regime created with scheduling irrigation at IW/CPE ratio of $0.6\left(\mathrm{I}_{1}\right), 0.8\left(\mathrm{I}_{2}\right)$ and $1.2\left(\mathrm{I}_{3}\right)$ at tasseling and dough stage (Fig. 2). The variation in leaf area index in response to varied nitrogen levels $\left(\mathrm{N}_{1}, \mathrm{~N}_{2}\right.$ and $\left.\mathrm{N}_{3}\right)$ ranged from 3.07 to 5.30 and irrigation scheduling $\left(\mathrm{I}_{1}, \mathrm{I}_{2}\right.$ and $\left.\mathrm{I}_{3}\right)$ ranged from 2.73 to 5.35 was explained by spectral band at yellow $(580 \mathrm{~nm})$, orange $(600 \mathrm{~nm})$ red $(660 \mathrm{~nm})$ and NIR $(800 \mathrm{~nm})$ regions with coefficient of determination $\left(R^{2}\right)$ of $98 \%$ (Table 2). This investigation culled out the potential of remote sensing for estimating biophysical parameters viz leaf nitrogen (\%), relative leaf water content $(\%)$ and leaf area index which are sensitive to environment and contributes to growth and yield of maize. These results in line with the findings of Blackmer et al. (1994, 1996) who reported that the reflectance around $550 \mathrm{~nm}$ or $610 \mathrm{~nm}$ in green region of spectrum has close correlation with nitrogen content in maize leaf. Different researchers have used reflectance at red and INR wavelengths in detection of nitrogen stress in maize crop (Walburg et al. 1982; Blackmer et al. 1996;
Table 1 The properties and specifications of spectroradiometer used in hyperspectral remote sensing in maize

\begin{tabular}{ll}
\hline Properties & Specifications \\
\hline Spectral range & $350 \mathrm{~nm}$ to $1000 \mathrm{~nm}$ \\
Linear range & 0 to 1.2 absorption units $(<0.5 \%)$ \\
Wavelength stability & $<0.001 \mathrm{~nm}$ per C \\
Base unit size & $15.5 \times 9.5 \times 4 \mathrm{~cm}$ \\
Signal-to-noise ratio & Up to $1000: 1$ \\
Wavelength resolution & $1.6 \mathrm{~nm}$ \\
Detector & 2048 pixel; 14 by $200 \mathrm{~nm}$ microelement array
\end{tabular}




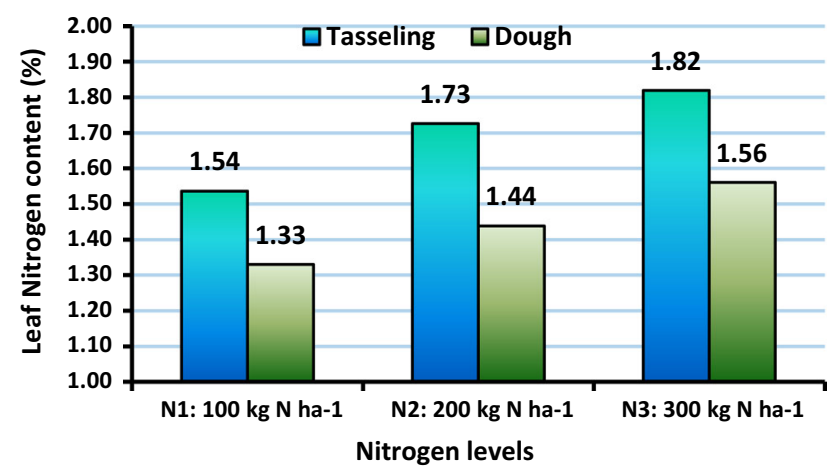

Fig. 1 Leaf nitrogen content (\%) of maize at tasseling and dough stages as influenced by nitrogen levels

Stone et al. 1996). Zhang and Zhou (2015) demonstrated that the canopy water information at the red edge of $680 \mathrm{~nm}-780 \mathrm{~nm}$. For prediction of leaf area index Zhao et al. (2007), used red edge bands $(690 \mathrm{~nm}-710 \mathrm{~nm}$ and $750 \mathrm{~nm}-900 \mathrm{~nm}$ ), Stagakis et al. (2010) combined green $(580 \mathrm{~nm})$, red edge $(700 \mathrm{~nm}$ and $710 \mathrm{~nm})$, and near infrared wavelengths $(1003 \mathrm{~nm})$; Haboudane et al. (2003) also combined green $(550 \mathrm{~nm})$, red $(670 \mathrm{~nm})$ and near infrared $(800 \mathrm{~nm}$ ) wavelengths (Table 2).

\section{Sensitivity of Spectral Reflectance to Age of the Crop}

The spectral reflectance pattern at different wavelengths was influenced by the age of the crop (Fig. 4). It was higher at tasseling stage when compared to dough stage. This evidences the relationships between reflectance in different spectral bands and phonological stages of the crop. A gradual decrease in NIR reflectance during the early reproductive stage and rapid drop toward senescence in corn was also reported by Nguy-Robertson et al. (2013). According to Liang (2004), in the visible part of the spectrum, absorption is due to pigments such as chlorophyll $a+b$ and carotenoids, while the near-IR and middleIR absorption by water is more important in the variation of reflectance (Figs. 3 and 4).

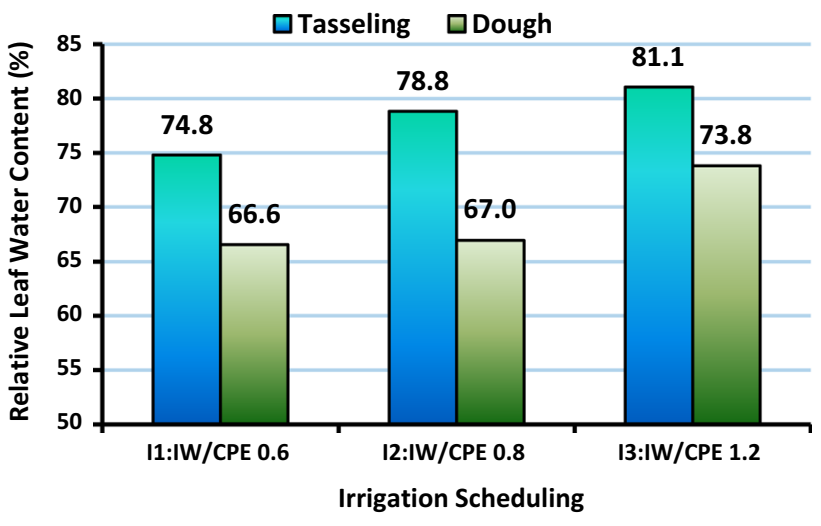

Fig. 2 Relative leaf later content $(\%)$ of maize as influenced by irrigation scheduling at tasseling and dough stage

\section{Reflectance Pattern of Different Biophysical Parameters Indicative Spectral Bands}

\section{a) Leaf Nitrogen (\%)}

At tasseling and dough stage of the crop, the spectral bands in NIR region $(780 \mathrm{~nm}$ and $860 \mathrm{~nm})$ and visible green region $(540 \mathrm{~nm})$ were found sensitive to leaf nitrogen content (Fig. 5a, b). The spectral reflectance of selected bands in NIR region and absorption in visible region was more at tasseling stage and decreased at dough stage of the crop. The higher reflectance in NIR region and more absorption in visible region represent the healthiness of the canopy. The crop nurtured with $300 \mathrm{~kg} \mathrm{~N} \mathrm{ha}^{-1}\left(\mathrm{~N}_{3}\right)$ appears healthier with higher leaf nitrogen content of $1.82 \%$ and $1.56 \%$ at tasseling and dough stages, respectively, when compared to medium $\left(\mathrm{N}_{2}\right)$ and low $\left(\mathrm{N}_{1}\right)$ nitrogen level canopy (Fig. 1). Therefore, $\mathrm{N}_{3}$ treatment exhibited more reflection of $60.9 \%$ and $51.1 \%$ at $780 \mathrm{~nm}$ wavelength and $57.8 \%$ and $41.7 \%$ at $860 \mathrm{~nm}$ wavelengths in NIR and more absorption of $13.1 \%$ and $14.6 \%$ at $540 \mathrm{~nm}$ in visible region at tasseling and dough stages, respectively, and these effects were reduced with decreasing the nitrogen dose from $\mathrm{N}_{2}\left(200 \mathrm{~kg} \mathrm{~N} \mathrm{ha}^{-1}\right)$ to $\mathrm{N}_{1}\left(100 \mathrm{~kg} \mathrm{~N} \mathrm{ha}^{-1}\right)$ level. Similar results were also reported by Min et al. (2006) and Xie et al. (2018) who demonstrated that $555 \mathrm{~nm}$ wavelength was the nitrogen

Table 2 Stepwise regression models for prediction of leaf nitrogen $(\%)$, relative leaf water continent (\%) and leaf area index in corn using spectral reflectance of identified bands in maize

\begin{tabular}{lclll}
\hline Parameters & Regression model & $R^{2}$ \\
\hline Leaf nitrogen $(\%)$ & $Y=0.444176+0.007781 \times R_{540}+0.009907 \times R_{780}+0.011622 \times R_{860}$ & 0.78 \\
Relative leaf water content $(\%)$ & $Y=28.75174+0.74338 \times R_{700}+0.39956 \times R_{740}+0.39321 \times R_{860}$ & 0.77 \\
Leaf area index & $Y=0.422930-0.069871 \times R_{580}+0.131964 \times R_{600}-0.067401 \times R_{660}+0.022995 \times R_{800}$ & 0.98 \\
\hline
\end{tabular}


Fig. 3 Leaf area index (LAI) of maize as influenced by irrigation scheduling and nitrogen levels at tasseling and dough stage

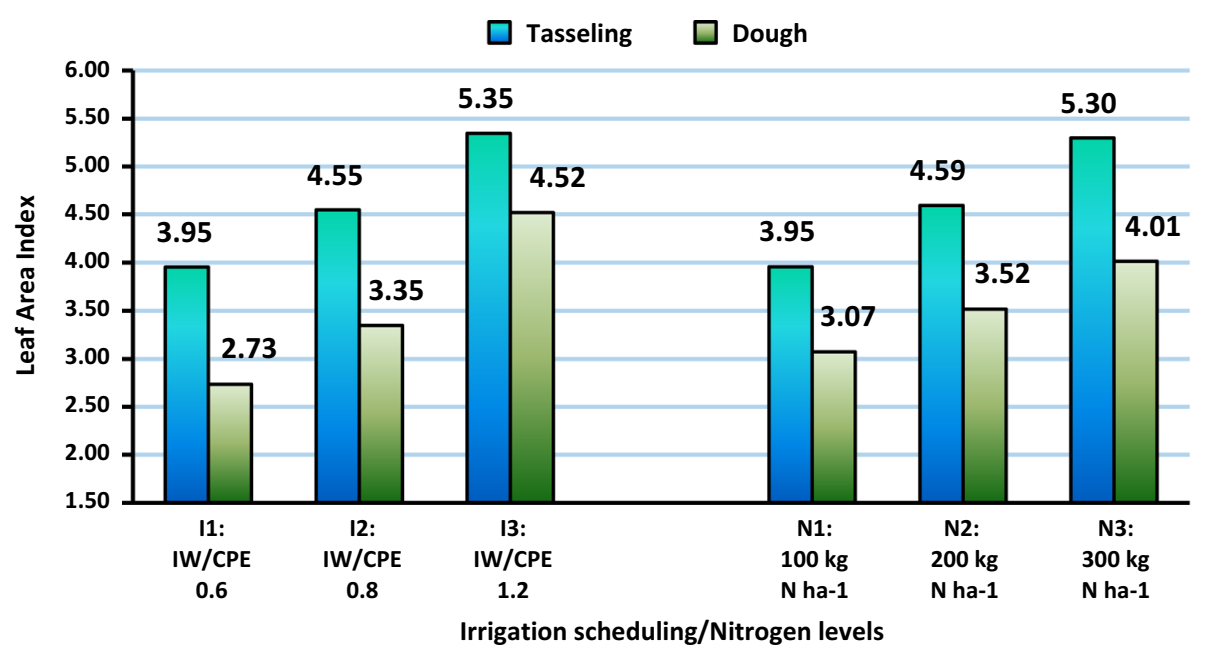

\section{b) Relative Leaf Water Content (\%)}

The differential relative leaf water content of maize leaf as a result of varied degrees of water stress imposed through irrigation scheduling influenced the reflectance pattern of selective wave bands at tasseling and dough stage of the crop (Fig. 6a, b). Under optimum irrigation scheduled at IW/CPE of $1.2\left(\mathrm{I}_{3}\right)$, the spectral reflectance of $50.0 \%$ and $47.2 \%$ at $700 \mathrm{~nm}$ and $56.5 \%$ and $39.1 \%$ at $860 \mathrm{~nm}$ in NIR region and $14.4 \%$ and $13.9 \%$ in visible green region at tasseling and dough stages, respectively, were more and decreased with increasing interval between two successive irrigations scheduled at $\mathrm{I}_{2}$ (IW/CPE of 0.8 ) and $\mathrm{I}_{1}$ (IW/CPE of 0.6) treatments. The more relative leaf water content under $I_{3}$ treatment allowed the crop to stay healthy at silking and dough stage of the crop growth (Fig. 2). The spectral region from 840 to $870 \mathrm{~nm}$ is sensitive to plant water stress in full canopy condition (DeTar et al. 2006; Govender et al. 2009). The higher reflectance from nonwater stressed crop than the stresses crop in NIR spectrum was also reported by Elmetwalli et al. (2012) and Weber

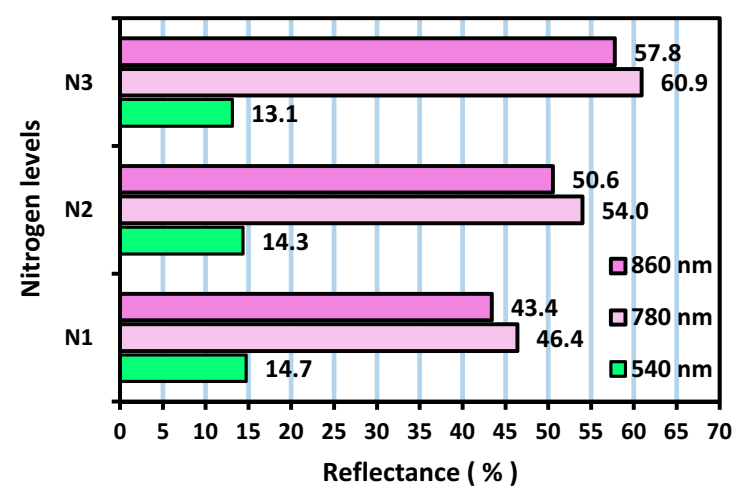

(a) Tasseling stage

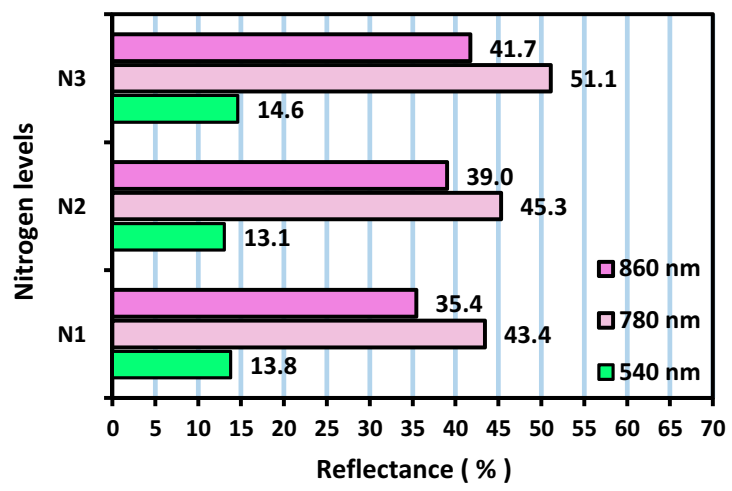

(b) Dough stage

Fig. 5 a and $\mathbf{b}$ Spectral reflectance of leaf nitrogen content indicative wave bands at tasseling and dough stage of maize as influenced by nitrogen levels 


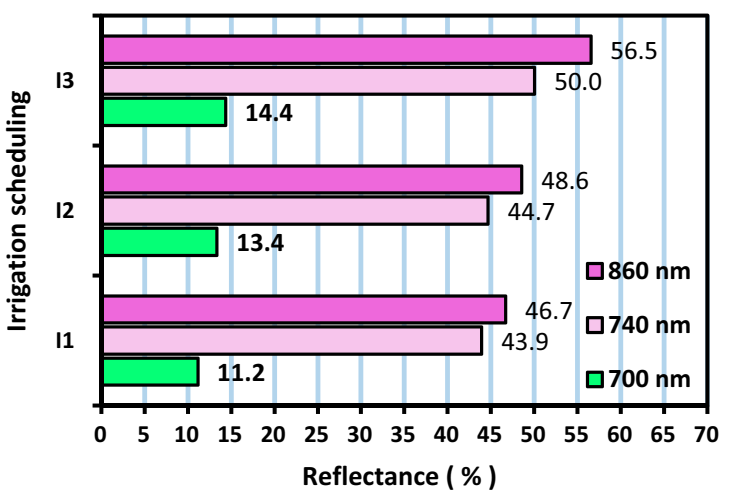

(a) Tasseling stage

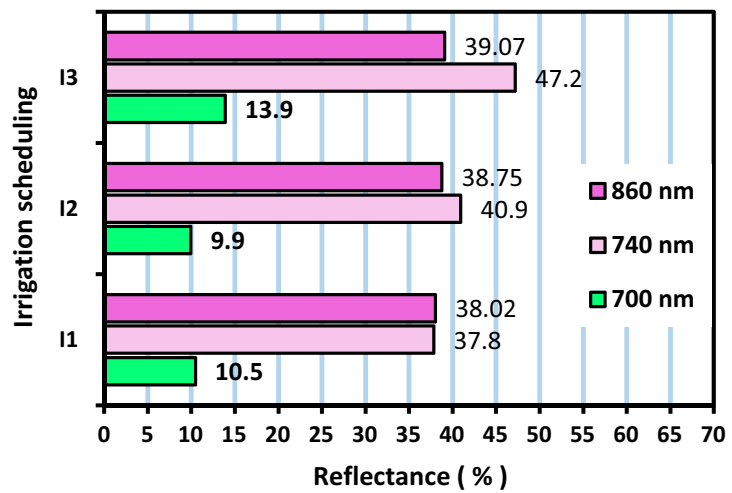

(b) Dough stage

Fig. 6 a and b Spectral reflectance of Relative leaf water content indicative wave bands at tasseling and dough stage of maize as influenced by irrigation scheduling

Fig. 7 a and b Spectral reflectance of leaf area index indicative wave bands at tasseling and dough stage of maize as influenced by irrigation scheduling and nitrogen levels

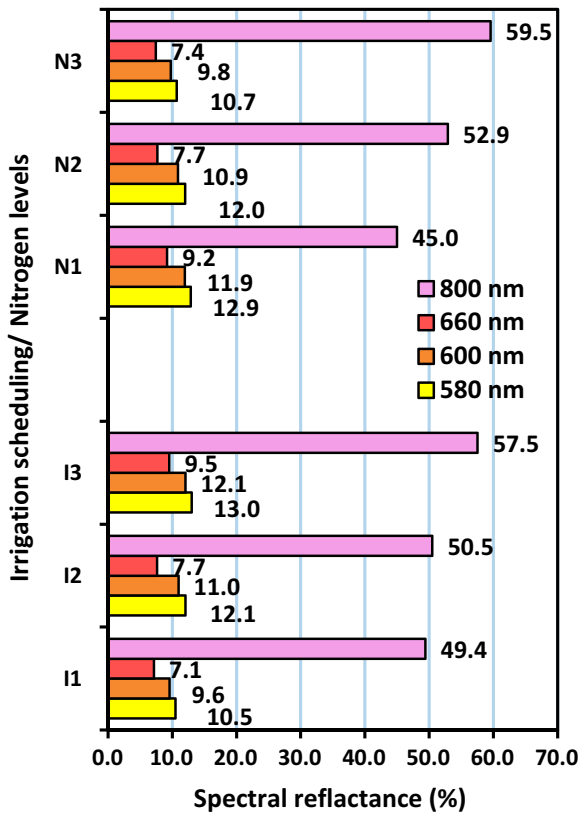

(a) Tasseling stage

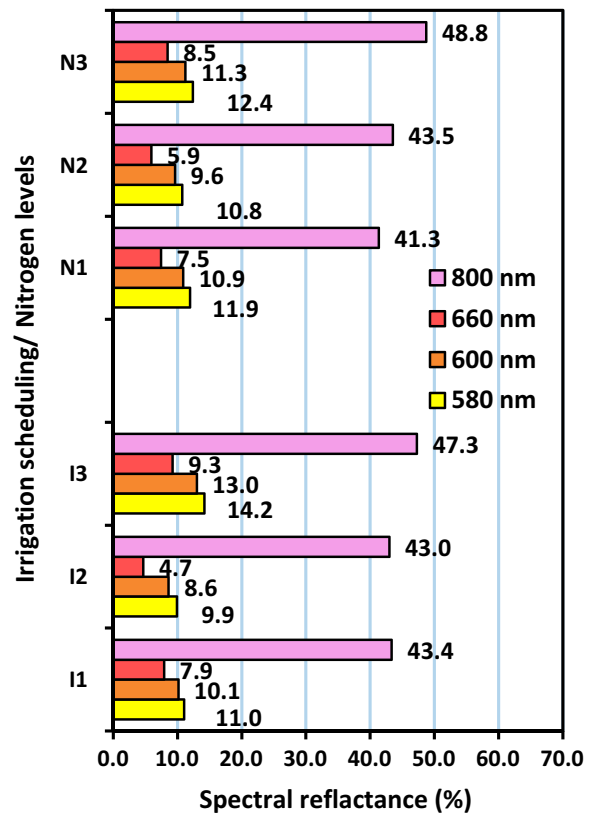

(b) Dough stage et al. (2012) in maize crop. The more reflectance in green region under $I_{3}$ treatment as compared to $I_{2}$ and $I_{1}$ treatments might be due to increase in biomass with increasing frequency between two successive irrigations resulted in dilution effect of mineral $\mathrm{N}$ concentration in different plant parts. Increased dry-weight accumulation accompanied by decreased shoot mineral concentration has been defined as a dilution effect (Jarrell and Beverly 1981). Greenwood et al. (1990) were also demonstrated that, the plant N\% decreases with increasing crop biomass.

\section{c) Leaf Area Index (LAI)}

The reflectance pattern of leaf area index indicative selected spectral bands at tasseling and dough stage is depicted in Fig. 7a, b, respectively. The leaf area index of the maize increased with decreasing interval between two subsequent irrigation ( $I_{1}$ to $I_{3}$ ) and increasing the nitrogen dose from $\mathrm{N}_{1}$ to $\mathrm{N}_{3}$ (Fig. 3). Higher leaf area index (LAI) is indicative of healthiness of the canopy. The reflectance at $800 \mathrm{~nm}$ in NIR region was higher at $\mathrm{I}_{3}(57.5 \%$ and $47.3 \%)$ and $\mathrm{N}_{3}(59.5 \%$ and $48.8 \%)$ levels at tasseling and dough stages, respectively, where maximum LAI was observed. The higher reflectance in yellow $(580 \mathrm{~nm})$, orange 

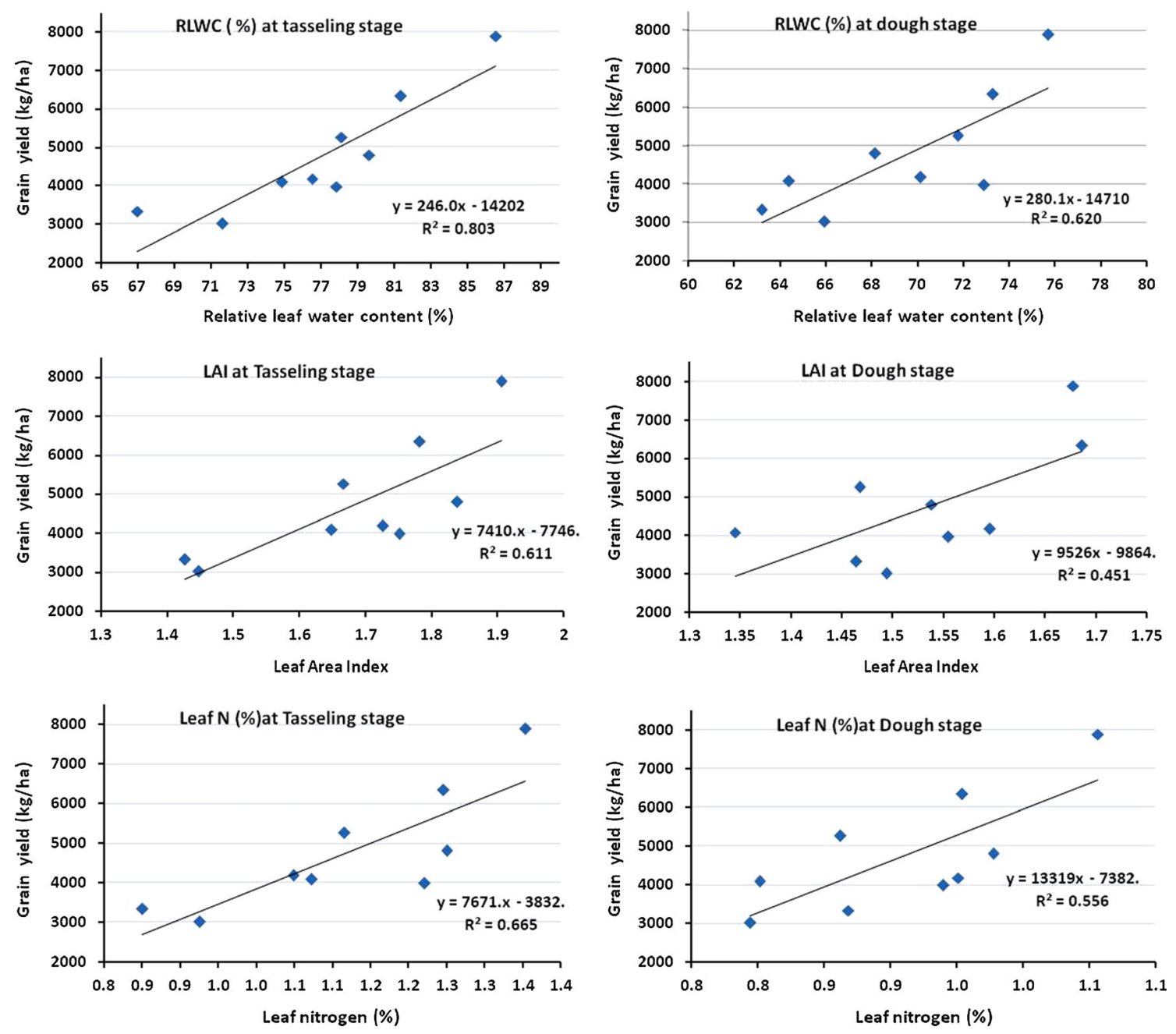

Fig. 8 Regression equations for prediction of grain yield ( $\mathrm{kg} / \mathrm{ha})$ based on derived biophysical parameters (relative leaf water content (RLWC \%), leaf area index (LAI) and leaf nitrogen contentment $(\mathrm{N}$

$\%)$ ) using reflectance (\%) from selective spectral bands at tasseling and dough stages of maize crop

$(600 \mathrm{~nm})$ and red $(660 \mathrm{~nm})$ in visible range under deficit irrigation scheduled at IW/CPE of $0.6\left(\mathrm{I}_{1}\right)$ and deficit nitrogen level of $100 \mathrm{~kg} \mathrm{~N} \mathrm{ha}^{-1}\left(\mathrm{~N}_{1}\right)$ treatment are the indicative of water stress and nitrogen stress resulted in reduction in LAI at tasseling and dough stages of the crop. These results clearly demonstrate that, the spectral bands viz. $580 \mathrm{~nm}, 600 \mathrm{~nm}, 660 \mathrm{~nm}$ and $800 \mathrm{~nm}$ were more sensitive to detect the effect water and nitrogen stress on leaf area index at tasseling and dough stages of maize crop.

\section{Prediction of Grain Yield Based on Spectral Reflectance-Derived Biophysical Parameters}

The regression equations for prediction of grain yield $(\mathrm{kg} /$ ha) based on derived biophysical parameters viz. relative leaf water content (RLWC \%), leaf area index (LAI) and leaf nitrogen contentment $(\mathrm{N} \%)$ using multiple regression equations (Table 1) which was developed based on

reflectance (\%) from selective spectral bands at tasseling and dough stages of maize crop is presented in Fig. 8. The results indicated that the derived biophysical parameters viz. relative leaf water content (RLWC \%), leaf area index (LAI) and leaf nitrogen contentment $(\mathrm{N} \%)$ at tasseling stage of maize crop accounted for $80 \%, 61 \%$ and $66 \%$ variation in grain yield, respectively. The predictive capabilities of these biophysical parameters for grain yield were comparatively low at dough stage of the crop. These results indicated that the biophysical parameters derived at tasseling stage based on regression equation developed from reflectance of selective wave bands were more sensitive for prediction of grain yield in maize crop. At dough stage (90 days after sowing), the maximum translocation of photosynthates/food material from source (leaves and stem) to sink (cob) occurs. The translocation of food material depends upon availability of soil moisture; active root mass, root shoot ratio, transpiration gradient from root 
to stomata, photosynthesis rate, stomatal conductance etc. These physiological activities tend to decrease from active growth phase (tasseling) to maturity stage. The reduction in these entire parameters become complex and thus increase the complexity in spectral reflectance patter as the crop tends to approach toward physiological maturity stage. Therefore, the yield predictive capability of spectral reflectance at dough stage might be low as compared to tasseling stage.

\section{Conclusions}

The potential for hyper-spectral remote sensing to detect water and nitrogen stress in irrigated maize was illustrated this investigation. Multiple linear regression analysis was performed using backward elimination stepwise method, and best combinations of bands were selected based on highest coefficient of determination for biophysical parameters viz. Leaf nitrogen (\%), relative leaf water content and leaf area index. The sensitiveness of spectral reflectance pattern at different wavelengths as influenced by water and nitrogen stress was illustrated. The sensitivity of spectral reflectance to age of the crop was established. The grain yield predictive capability of derived biophysical parameters viz. relative leaf water content (RLWC \%), leaf area index (LAI) and leaf nitrogen contentment (N \%) using multiple regression equations which was developed based on reflectance (\%) from selective spectral bands at tasseling stage of maize crop was tested and found effective. This investigation culled out the most effective spectral bands in visible and infrared region for detection of water and nitrogen stress in maize crop. The outcome of this study may be useful for choosing effective spectral bands for multispectral remote sensing for assessing maize crop condition at spatiotemporal scale on real-time basis.

Acknowledgements This work was supported and funded by the Department of Science and Technology (DST) India under the Project "Data Science-based Farming Support System For Sustainable Crop Production Under Climatic Changes (DSFS)" Project No: MST/ IBCD/EE/F066/2016-17G48 and also Professor Jayashankar Telangana State Agricultural University for providing all amenities for conducting research work.

Open Access This article is licensed under a Creative Commons Attribution 4.0 International License, which permits use, sharing, adaptation, distribution and reproduction in any medium or format, as long as you give appropriate credit to the original author(s) and the source, provide a link to the Creative Commons licence, and indicate if changes were made. The images or other third party material in this article are included in the article's Creative Commons licence, unless indicated otherwise in a credit line to the material. If material is not included in the article's Creative Commons licence and your intended use is not permitted by statutory regulation or exceeds the permitted use, you will need to obtain permission directly from the copyright holder. To view a copy of this licence, visit http://creativecommons. org/licenses/by/4.0/.

\section{References}

Barrs, H. D., \& Weatherley, P. E. (1962). A re-examination of the relative turgidity techniques for estimating water deficits in leaves. Australian Journal of Biological Sciences, 15, 413-428.

Blackmer, T. M., Schepers, J. S., \& Varvel, G. E. (1994). Light reflectance compared with other nitrogen stress measurements in corn leaves. Agronomy Journal, 86(6), 934-938.

Blackmer, T. M., Schepers, J. S., Varvel, G. E., \& Walter-Shea, E. A. (1996). Nitrogen deficiency detection using reflected shortwave radiation from irrigated corn canopies. Agronomy Journal, 88(1), $1-5$.

Darvishzadeh, R., Skidmore, A., Schlerf, M., Atzberger, C., Corsi, F., $\&$ Cho, M. (2008). LAI and chlorophyll estimation for heterogeneous grassland using hyperspectral measurements. International Journal of Remote Sensing, 63(4), 409-426.

DeTar, W. R., Penner, J. V., \& Funk, H. A. (2006). Airborne remote sensing to detect plant water stress in full canopy cotton. Transactions-American Society of Agricultural Engineers, 49(3), 655-666.

Di Paolo, E., \& Rinaldi, M. (2008). Yield response of corn to irrigation and nitrogen fertilization in a Mediterranean environment. Field Crops Research, 105, 202-210.

Elmetwalli, A. M. H., Tyler, A. N., Hunter, P. D., \& Salt, C. A. (2012). Detecting and distinguishing moisture-and salinityinduced stress in wheat and maize through in situ spectro radiometry measurements. Remote Sensing Letters, 3(4), 363-372.

Food and Agricultural Organization (FAO). (2017). FAO statistical databases. https://faostat.fao.org/. Retrived 8 Jan 2020.

Gheysari, M., Mirlatifi, S. M., Bannayan, M., Homaee, M., \& Hoogenboom, G. (2009). Interaction of water and nitrogen on maize grown for silage. Agriculture Water Management, 96, $809-821$.

Govender, M., Govender, P. J., Weiersbye, I. M., Witkowski, E. T. F., \& Ahmed, F. (2009). Review of commonly used remote sensing and ground-based technologies to measure plant water stress. Water SA, 35(5), 741-752.

Greenwood, D. J., Lemaire, G., Gosse, G., Cruz, P., Draycott, A., \& Neeteson, J. J. (1990). Decline in percentage $\mathrm{N}$ of $\mathrm{C}_{3}$ and $\mathrm{C}_{4}$ crops with increasing plant mass. Annals of Botany, 66(4), $425-436$.

Haboudane, D., Miller, J. R., Pattey, E., Zarco-Tejada, P. J., \& Strachan, I. B. (2003). Hyperspectral vegetation indices and novel algorithms for predicting green LAI of crop canopies: Modeling and validation in the context of precision agriculture. Remote Sensing of Environment, 90(3), 337-352.

Jarrell, W. M., \& Beverly, R. B. (1981). The dilution effect in plant nutrition studies. Advances of Agronomy, 34, 197-224.

Liang, S. (2004). Quantitative remote sensing of land surfaces. (Wiley and Sons, Ed.) Wiley series on remote sensing. Hoboken: Wiley. https://doi.org/10.1002/047172372X.

Min, M., Lee, W. S., Kim, Y. H., \& Bucklin, R. A. (2006). Nondestructive detection of nitrogen in Chinese cabbage leaves using VIS-NIR spectroscopy. HortScience, 41(1), 162-166.

Nguy-Robertson, A., Gitelson, A., Peng, Y., Walter-Shea, E., Leavitt, B., \& Arkebauer, T. (2013). Continuous monitoring of crop reflectance, vegetation fraction, and identification of developmental stages using a four band radiometer. Agronomy Journal, 105(6), 1769-1779. 
Panigada, C., Busetto, L., Meroni, M., Amaducci, S., Rossini, M., Cogliati, S., Boschetti, M., Picchi, V., Marchesi, A., Pinto, F., Rascher, U., \& Colombo, R. (2010). EDOCROS: Early detection of crop water and nutritional stress by remotely sensed indicators. In 4th International workshop on remote sensing of vegetation fluorescence, 15-17 NOV. 2010, Valencia (SPAIN).

Piper, C. S. (1966). Soil and plant analysis. New York: Inter Science Publisher.

Stagakis, S., Markos, N., Sykioti, O., \& Kyparissis, A. (2010). Monitoring canopy biophysical and biochemical parameters in ecosystem scale using satellite hyperspectral imagery: An application on a Phlomisfruticosa Mediterranean ecosystem using multiangular CHRIS/PROBA observations. Remote Sensing of Environment, 114(5), 977-994.

Stone, M. L., Solie, J. B., Raun, W. R., Whitney, R. W., Taylor, S. L., \& Ringer, J. D. (1996). Use of spectral radiance for correcting in-season fertilizer nitrogen deficiencies in winter wheat. Transactions of the ASAE, 39(5), 1623-1631.

Walburg, G. M. M. E., Bauer, M. E., Daughtry, C. S. T., \& Housley, T. L. (1982). Effects of nitrogen nutrition on the growth, yield, and reflectance characteristics of corn canopies. Agronomy Journal, 74(4), 677-683.

Watson, D. J. (1952). The physiological basis of variation in yield. Advances in Agronomy, 4, 101-145.
Weber, V. S., Araus, J. L., Cairns, J. E., Sanchez, C., Melchinger, A. E., \& Orsini, E. (2012). Prediction of grain yield using reflectance spectra of canopy and leaves in maize plants grown under different water regimes. Field Crops Research, 128, 82-90.

Xie, C., Yang, C., Hummel, A., Johnson, G. A., \& Izuno, F. T. (2018). Spectral reflectance response to nitrogen fertilization in field grown corn. International Journal of Agricultural and Biological Engineering, 11(4), 118-126.

Zhang, F., \& Zhou, G. (2015). Estimation of canopy water content by means of hyperspectral indices based on drought stress gradient experiments of maize in the north plain China. Remote Sensing, 7(11), 15203-15223.

Zhao, D., Huang, L., Li, J., \& Qi, J. (2007). A comparative analysis of broadband and narrowband derived vegetation indices in predicting LAI and CCD of a cotton canopy. ISPRS Journal of Photogrammetry and Remote Sensing, 62(1), 25-33.

Publisher's Note Springer Nature remains neutral with regard to jurisdictional claims in published maps and institutional affiliations. 